\title{
$\bigwedge_{\text {GEQGRALIEO }}^{\operatorname{TTELIE}}$
}

\section{Análise integrada para conservação ambiental: estudo aplicado ao Parque Estadual de Paraúna - Goiás}

\author{
Integrated analysis for environmental conservation: a study \\ applied to the Paraúna State Park-Goiás
}

\section{Análisis integrado para la conservación ambiental: estudio aplicado al Parque Estatal de Paraúna - Goiás}

\author{
Delerman Teixeira do Amaral Neto \\ Universidade Federal de Goiás \\ ddelerman@gmail.com
}

Cláudia Valéria de Lima

Universidade Federal de Goiás

claudia@ufg.br

\begin{abstract}
Resumo
O presente artigo pretende fazer uma revisão de referenciais teóricos que elucidam a temática da conservação dos ambientes naturais em contrapartida ao avanço da sociedade contemporânea progressista do século XXI. Para isto, a utilização de estudos correspondentes ao planejamento ambiental, geoconservação, geodiversidade e patrimônio geológico, além da simplificação do arcabouço legislativo relativos ao meio ambiente, darão suporte necessário à composição deste artigo. Como exemplo de recorte espacial a fim de compreender as efetivas políticas de ordenamento, gestão e preservação ambiental no território brasileiro e, em especial no Estado de Goiás, buscou-se contemplar à pesquisa um estudo territorial aplicado ao Parque Estadual de Paraúna, localizado no município de Paraúna. Foram diagnosticadas, a priori, ineficiências político-institucionais dos órgãos representativos na elaboração/execução de projetos que visam à conservação dos ambientes naturais conforme previsto na legislação ambiental brasileira. $\mathrm{O}$ baixo indicativo da terminologia voltada à geoconservação e patrimônio geológico na legislação, inexistência em plano de manejo, acesso rodoviário com alto índice de periculosidade e degradação do patrimônio público são as principais análises contempladas nesta pesquisa.
\end{abstract}

Palavras-chave: Parque Estadual de Paraúna; geodiversidade; geoconservação; SNUC. 


\begin{abstract}
This article intends to review theoretical frameworks that elucidates the conservation of natural environments in contrast to the progress of contemporary progressive society in the 21 st century. For this, the use of studies corresponding to environmental planning, geoconservation, geodiversity and geological heritage, as well as the simplification of the law related to the environment, will provide the necessary support for the composition of this article. As an example of a spatial cut-off in order to understand the effective planning, management and environmental preservation policies in the Brazilian territory, and especially in the State of Goiás, a territorial study was applied to the Paraúna State Park located in the municipality of Paraúna. A priori, political-institutional inefficiencies of the representative bodies were diagnosed in the elaboration / execution of projects that aim at the conservation of the natural environments according to plan in Brazilian environmental legislation. The low indicative of terminology geoconservation and geological heritage in the legislation, absence of management plan, road access with high risk index and degradation of public assets are the main analyzes contemplated in this research.
\end{abstract}

Keywords: Paraúna State Park; geodiversity; geoconservation; SNUC.

\title{
Resumen
}

El presente artículo discute los referenciales teóricos que esclarecen la temática de la conservación de los ambientes naturales en contrapartida al avance de la sociedad contemporánea progresista del siglo XXI. La utilización de estudios correspondientes a la planificación ambiental, geoconservación, geodiversidad y patrimonio geológico, además de la simplificación del marco legislativo relativo al medio ambiente, darán soporte a este artículo. Como recorte espacial a fin de comprender las efectivas políticas de planificación, gestión y preservación ambiental en el territorio brasileño y en especial en el Estado de Goiás, se buscó un estudio territorial aplicado al Parque Estadual de Paraúna. Se han diagnosticado ineficiencias político-institucionales de los órganos representativos en la elaboración/ejecución de proyectos que apuntan a la conservación de los ambientes naturales previstos en la legislación ambiental brasileña. El bajo indicativo de la terminología orientada a la geoconservación y patrimonio geológico en la legislación, inexistencia en el plan de manejo, acceso vial con alto índice de peligro y degradación del patrimonio público son los principales análisis que son examinados en esta investigación.

Palabras clave: Parque Estatal de Paraúna; geodiversidad; geoconservación; SNUC.

\section{Introdução}

No decorrer do século XX agentes institucionais e comunidade civil internacional debateram a problemática da poluição dos ambientes naturais frente ao impositivo avanço das sociedades modernas. Não obstante, alertas sobre a importância do contingenciamento ambiental foram alavancados por meio de ideais ecológicos que pressupõe ao uso e conservação sustentável dos recursos naturais na esfera global.

Essas preliminares ambientais ganharam escopo, em definitivo, no debate político institucional por meio das realizações das Conferências das Nações Unidas sobre o Meio Ambiente. A partir de então foram demandados acordos multilaterais entre os 
países-membros da cúpula da ONU no intuito de reavaliar alternativas que minimizassem a supressão dos meios naturais, à procura de soluções que inibissem a degradação biológica, física e química dos sistemas terrestres exponencialmente (SANTOS, 2004).

O Brasil, que sediou duas das principais conferências sobre a temática do desenvolvimento sustentável, 1992 e 2002, passou por ativas reformulações jurídicas neste ínterim, no intuito de não se imiscuir da responsabilidade de garantia da conservação de seus ambientes naturais. As primeiras legislações elaboradas no País referentes ao contingenciamento dos recursos naturais estão esboçadas no primeiro Código Florestal (Decreto $\mathrm{n}^{\circ} 23.793$ de 10 de julho de 1934) e no primeiro Código de Águas (Decreto $\mathrm{n}^{\circ}$ 24.263 de 10 de julho de 1934). Atualmente, a Política Nacional de Meio Ambiente (PNMA) de 1981, a Constituição Federal (CF) de 1988 e o Sistema Nacional de Unidades de Conservação (SNUC) de 2000, são as principais normativas jurídicas abrangentes à temática ambiental na esfera federal e que implicam aporte regulador para elaboração de iniciativas em políticas públicas e/ou investimentos privados voltados ao desenvolvimento econômico e sustentável no território nacional.

Embora com vasto mecanismo jurídico-ambiental referente à temática da conservação ambiental, o entendimento aplicado dessas legislações remetem múltiplas interpretações na sociedade e no corpo jurisdicional do País. Por suportar limites territoriais de nível continental, de espessa diversidade natural e singularidades regionais, o Estado brasileiro ainda abarca contradições socioambientais que demandam ações próprias aos planos de organização ambiental e territorial referente ao tema.

A implementação das Unidades de Conservação (UC's) foi uma das intercessões orientada pelo SNUC com fins de resguardar áreas potencialmente características em remanescentes ecológicos (SNUC, 2000). Entretanto, em sua grande maioria, as UC's promulgadas no País, ainda hoje demandam por incentivos do Poder Público seja por recursos financeiros, recursos humanos, elaboração de planos de manejo, infraestrutura, controle, monitoramento e fiscalização ambiental, além de resoluta regularização litigiosa em processos fundiários.

Presentemente, as UC's consideradas no SNUC estão organizadas em dois grupos: A) Unidades de Proteção Integral e B) Unidade de Uso Sustentável. Dentro destas categorias mencionadas, os Parques (cujo enquadramento legal foi alocado na categoria "A" citado acima), correspondem aos que apresentam maiores reservas de proteção ambiental no país por $\mathrm{km}^{2}$. Em Goiás há mais de 92 UC's, das quais, 03 são Parques Federais e 22 são Parques Estaduais. As demais UC's condizem às outras categorias (MMA, 2017).

Sobre esta perspectiva, utilizou-se como exemplo ilustrativo para elaboração desta pesquisa o recorte espacial do Parque Estadual de Paraúna (PEPa), localizado no município de Paraúna, Estado de Goiás. Decretado como categoria de Parque Estadual pela Lei Estadual do Estado de Goiás n 5.568, de 18 de março de 2002, a respectiva UC tem potencial grau significativo em remanescentes de espécies biológicas do Bioma 
Cerrado, além de representar peculiar característica geomorfológica para conservação ambiental em patrimônio natural no Estado de Goiás.

O PEPa é o único em Goiás com relevos ruiniformes ${ }^{1}$, característicos de geossítios $^{2}$ que vislumbram o imaginário humano por configurar imagens lúdicas em suas rochas esculpidas decorrentes de ações erosivas diferenciais. No Brasil os Parques com representatividade em geossítios são poucos. Como exemplos há o Parque Estadual de Vila Velha localizado no município de Ponta Grossa-PR, o Parque Nacional Chapada das Mesas localizado no centro-sul do Estado do Maranhão e o Parque Nacional das Setes Cidades localizado no Estado do Piauí.

Desta maneira, o presente trabalho pretende discutir a articulação entre os eixos normativos de cunho ambiental que foram promulgados pelo governo brasileiro no desenrolar da história da conservação ambiental, dando ênfase às políticas adotadas para criação de UC's, em especial na categoria de Parques. Assim, diagnosticar-se-á efetiva aplicação da legislação brasileira em políticas públicas, correlacionando-as com instrumentos teóricos relacionados ao desenvolvimento sustentável, obtendo, por fim, uma dinâmica técnica no qual denominamos por: análise integrada para conservação ambiental.

\section{Procedimentos metodológicos}

A metodologia utilizada para realização desta pesquisa consistiu em três partes, a saber: a) pesquisa bibliográfica, b) estudo aplicado em trabalhos de campo ao Parque Estadual de Paraúna e, c) utilização de ferramentas geotecnológicas para processamento de imagens cartográficas da área de estudo.

$\mathrm{Na}$ primeira etapa, levantamentos de dados/qualificação dos documentos referentes ao ordenamento jurídico brasileiro (legislações ambientais), decretos estaduais e bibliografia teórica produzida por autores que pesquisam temas correlatos ao planejamento ambiental, geodiversidade, geoconservação e patrimônio geológico propiciaram os instrumentos necessários para elaboração do artigo. Pesquisas realizadas em periódicos acadêmicos, bibliotecas físicas e online e banco de dados governamentais fortaleceram o embasamento teórico desta pesquisa, de modo que, a partir delas, leituras e fichamentos dos textos foram essenciais ao esclarecimento opinativo dos autores.

Em um segundo momento, trabalhos de campo para vistoria técnica da área de estudo, registros fotográficos da paisagem e dos geossítios, além de fichamentos em planilhas

\footnotetext{
1 "Relevos que [...] podemos observar formas bizarras, com aspectos ruiniforme devido à erosão que ataca os arenitos e quartzitos que reagem de modo diferente à ação erosiva" (GUERRA, 1993, p. 370).

2 "Geossítio é ocorrência de um ou mais elementos da geodiversidade, bem delimitado geograficamente e que apresente valor singular do ponto de vista científico, pedagógico, cultural, turístico" (BRILHA, 2005, p.52).
} 
preestabelecidas anteriormente ao campo, ajudaram estabelecer parâmetros informativos da área de estudo. Foram realizadas tomadas fotográficas e análise do parque, como exemplos das vias de acesso ao $\mathrm{PEPa}$, infraestrutura local e registros de degradação nas rochas.

Na última etapa de trabalho, foram confeccionados produtos cartográficos da área de estudo a partir de vetores georreferenciados disponíveis no site do SIEG (Sistema de Informação Estadual de Geoinformação/GO). A utilização do software ArcGis 10.1 aliados ao banco de dados do referido órgão governamental, disponíveis no endereço eletrônico http://www.sieg.go.gov.br, forneceram base significativa a produção dos mapas cartográficos.

A aquisição de dados vetoriais dos municípios do Estado de Goiás em 2017 em escala de 1:100.000, dados das unidades geológicos de 2008 em escala de 1:500.000, das unidades de uso sustentável de 2006 em 1:1.000.000, todas convertidas ao datum SIRGAS 2000, foram os shapefiles necessários a criação dos mapas cartográficos deste trabalho.

\section{Caracterização da área de estudo}

Localizado na Mesorregião Sudoeste do Estado de Goiás, o município de Paraúna possui área aproximada de $3.800 \mathrm{~km}^{2}$, cujo limite territorial divide com outros 11 (onze) municípios, conforme demonstrado na Figura 1 (IBGE, 2016; SIEG, 2017).

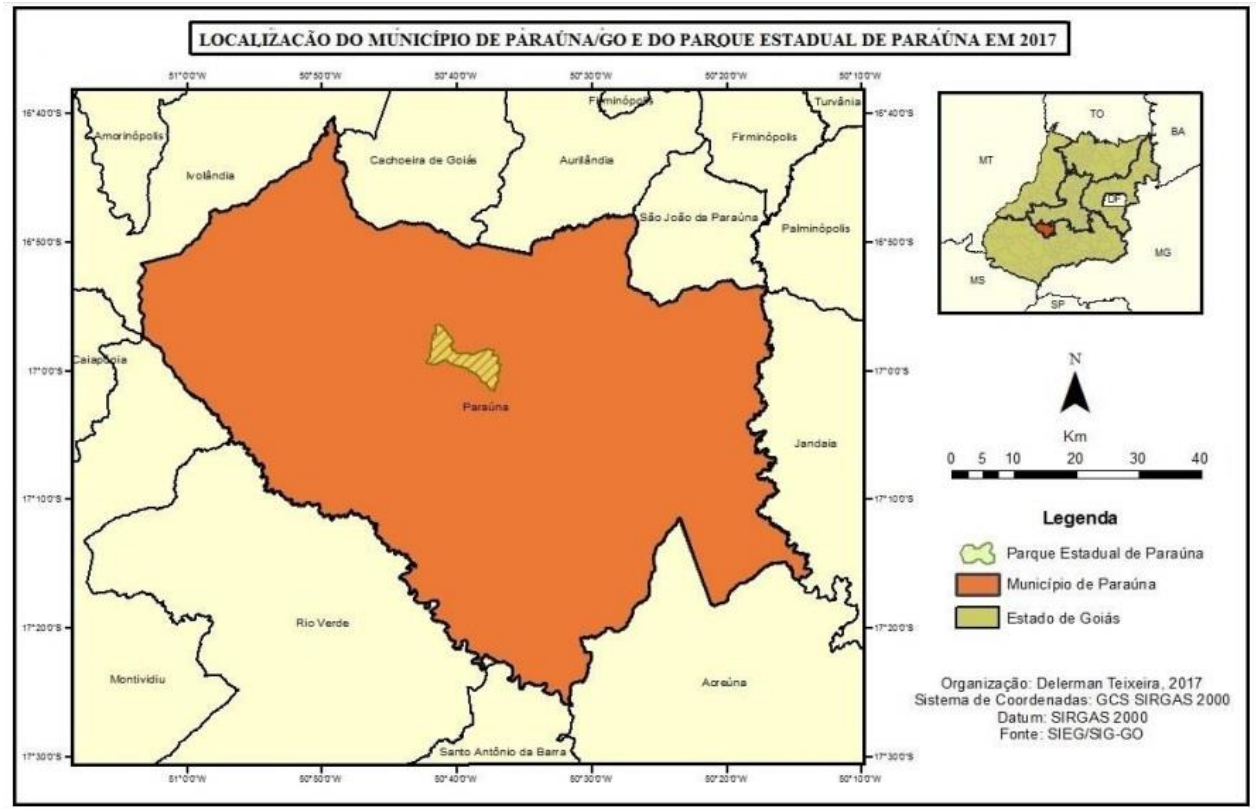

Figura 01. Limite político-administrativo do munícipio de Paraúna/GO e do Parque Estadual de Paraúna. Org: Teixeira, D. 2017. 
De acordo com Ferreira (2017), o município de Paraúna situa-se sobre 12 (doze) tipologias geológicas cuja origem cronológica variam desde o Período Neoproterozóico (1 Ba. à 545 Ma.) ao Período Pleistoceno (1.8 Ma. à 0,15 Ma.). Dentre essas unidades geológicas, o PEPa encontra-se localizado na porção N-E do Planalto da Bacia Sedimentar do Paraná, Formação Aquidauana, subunidade do Grupo Itararé (FERREIRA, 2017; RADAMBRASIL, 1983; GOIÁS, 2008).

Segundo Goiás (2008), a Bacia Sedimentar do Paraná “é uma extensa estrutura intracratônica desenvolvida sobre a crosta continental e tem cerca de $1.400 .000 \mathrm{~km}^{2}$ " dos quais perfazem limites nacionais com Brasil, Uruguai, Paraguai e Argentina. (GOIÁS, 2008). Ainda segundo o autor, o desenvolvimento desta bacia sedimentar revela-se pela fragmentação do antigo Continente Godwana, do qual possui $5.000 \mathrm{~m}$ em rochas sedimentares e vulcânicas estratificadas. Dentre as rochas sedimentares e seu período de deposição há variação cronológica entre o Ordoviciano e Cretáceo inferior (GOIÁS, 2008; apud Schneider et. al. 1974).

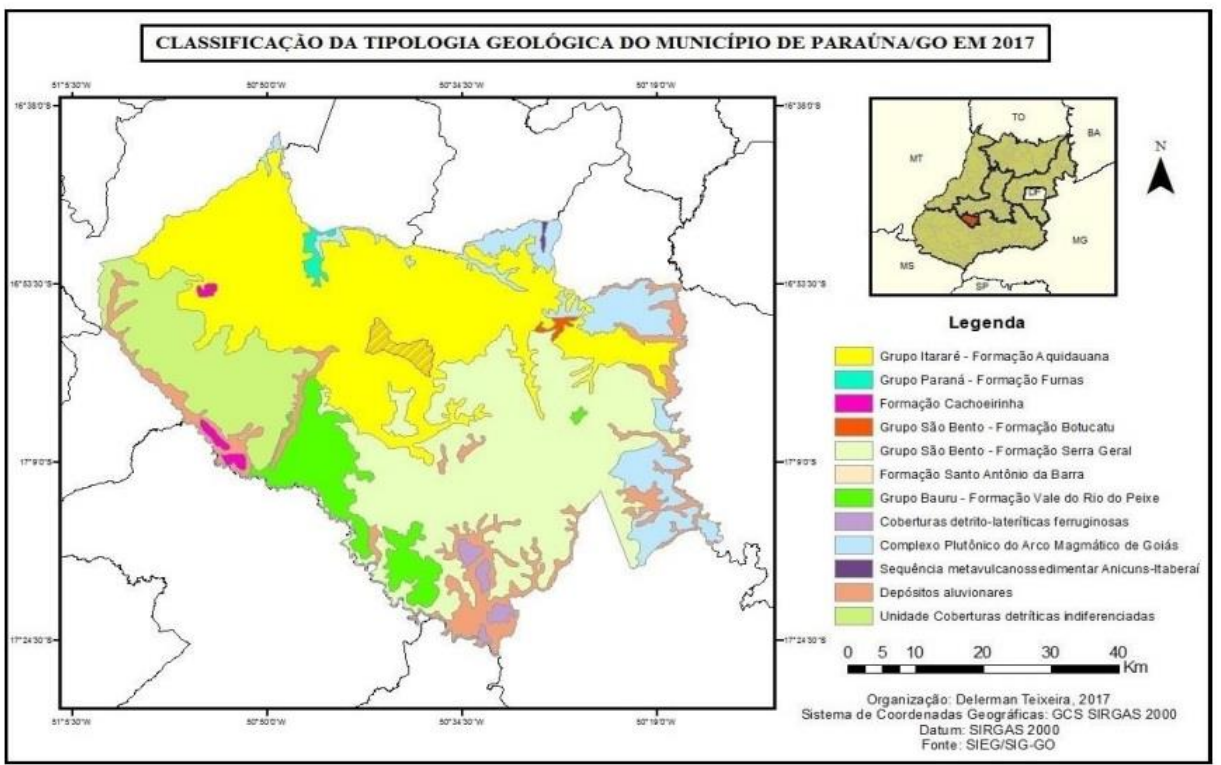

Figura 02. Classificação da tipologia geológica do município de Paraúna/ GO. Org: Teixeira, N,, 2017.

Em Goiás (2008), ressalta-se que o registro geológico da Bacia do Paraná é representado pela Formação Piranhas, além dos grupos Bauru, Itararé, Paraná, Rio Avaí e São Bento. Neste caso específico, o Grupo Itararé, o qual está inserido no substrato geológico do $\mathrm{PEPa}$, representado pela Formação Aquidauana, é composto 
predominantemente por rochas areníticas. Embora, segundo o Ferreira (2017) e Goiás (2008), possam ser encontrados siltitos, argilitos, diamictitos, dentre outras características litológicas.

A deposição litológica da Formação Aquidauana pode inquirir indicativos de deposição em ambientes fluviais e lacustres, além da sugestão em ambientes de glaciação próxima (GOIÁS, 2008). A Figura 2 demonstra a variabilidade geológica encontrada no município de Paraúna, em especial, a especificação litológica do PEPa.

Decretado pela Lei Estadual do Estado de Goiás no 5.568 , de 18 de março de 2002, o PEPa revela-se importante em contingenciar aspectos referente a biodiversidade do Bioma Cerrado e representa peculiar característica geomorfológica para fins de preservação do patrimônio geológico para o estado de Goiás. Por ser considerado o único em relevos ruiniformes, o PEPa vislumbra o imaginário humano por configurar imagens lúdicas em suas rochas esculpidas decorrentes de ações erosivas diferencial (Figura 3).

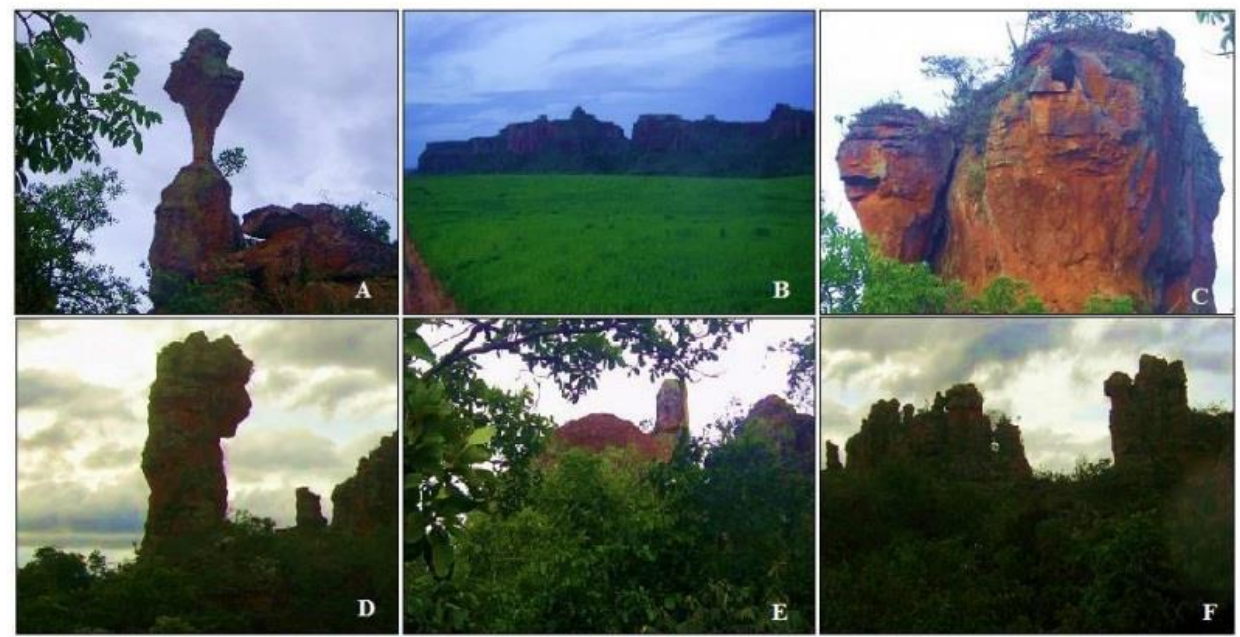

Figura 03. Imagens fotográficas das rochas areníticas do Parque Estadual de Paraúna: (a) Pedra do Cálice; (b) Serra da Portaria; (c) Rocha fragmentária em novo cálice; (d) Pedra do Índio; (e) Pedra da Tartaruga; (f) Rochas ruiniformes.

Fonte: Acervo dos Autores. Org: Teixeira, D. 2017.

\section{Planejamento ambiental, legislação ambiental, geodiversidade, geoconservação e patrimônio geológico}

A análise holística-integrada para fins de planejamento ambiental, de acordo com Ross (2009) e Santos (2004), interpreta a superfície terrestre como resultado constante dos fenômenos naturais (dinâmica biótica-abiótica) em consonância com as ações antrópicas 
(processos de urbanização, industrialização, agropecuários, infraestruturas, etc.). Assim, susceptíveis modelagens no estrato geográfico são definidas por meio das relações culturais e perspectivas sociais em escalas temporais distintas (ROSS, 2009; SANTOS, 2004).

Dentro de uma cronologia acadêmica e científica, as pesquisas referentes à conservação dos ambientes geológicos datam do início da década de 1990, quando autores adotaram o conceito de geodiversidade para explicar a variedade do substrato geológico com a finalidade de elaborar parâmetros conservativos ao uso e ocupação desses ambientes abióticos em suas multifunções (NASCIMENTO et. al. 2008). Nesse sentido, lacunas ainda existentes reverberam intenções aos estudos e aplicações de práticas de planejamento ambiental em unidades de conservação, principalmente, quando tratado de assuntos relacionados à geodiversidade, geoconservação e patrimônio geológico (BRILHA, 2005; GRAY, 2013).

Para Santos (2004), o planejamento ambiental está incorporado à perspectiva conceitual de desenvolvimento sustentável modulada nas últimas décadas pela comunidade global. Há uma correlação direta ao contingenciamento dos estoques dos recursos naturais atrelados a uma qualidade de vida habitável para às populações presentes e futuras. Segundo o autor, o conceito de planejamento ambiental na comunidade científica não é consensual, porém, detém equivalentes semelhanças ao esboço a seguir,

o planejamento ambiental fundamenta-se na interação e integração de sistemas que compõem o ambiente. Tem o papel de estabelecer as relações entre os sistemas ecológicos e os processos da sociedade, das necessidades socioculturais a atividades de interesses socioeconômicos, a fim de manter a máxima integridade possível dos seus elementos componentes (SANTOS, 2004, p.28).

Nesse sentido, para o entendimento das práticas de planejamento ambiental no território brasileiro, é necessário correlacionar os eixos jurisdicionais promulgados para conservação dos sistemas naturais, isto é, cuja prática institucional exprimida em políticas públicas diz respeito ao embasamento teórico do ordenamento jurídico e legislações pertinentes à temática. Assim, os registros da Política Nacional de Meio Ambiente (PNMA) de 1981, o Art. 225 da Constituição Federal (CF) de 1988 - o qual dispõe a soma dos direitos e deveres jurídico-administrativos da União e sociedade civil -, o Sistema Nacional de Unidades de Conservação (SNUC) de 2000 e o Sistema Estadual de Unidades de Conservação do Estado de Goiás (SEUC) de 2002, fornecem sustentáculo à elaboração de análises para conservação ambiental e, consequentemente, ações de planejamento ambiental traduzidas no território nacional.

Seguindo este panorama legislativo, o qual a interpretação normativa das leis nos versa sobre as pré-condições estabelecidas às práticas de planejamento ambiental de caráter institucional, a Lei 6.938/81 que institui o PNMA, em seu Art. $2^{\circ}$, dispõe, 
A Política Nacional de Meio Ambiente tem por objetivo a preservação, melhoria e recuperação da qualidade ambiental propícia à vida, visando assegurar, ao País, condições de desenvolvimento socioeconômico, aos interesses da segurança nacional e à proteção da dignidade da vida humana [...] (BRASIL, 1981).

Impulsionado pela PNMA, a CF de 1988, marcou a história legislativa brasileira em jurisdições sobre contensão dos recursos naturais do País (SILVA, 2001). Ainda segundo Silva (2001), como carta magna idealizadora das atividades institucionais do Estado e sociedade civil, a mesma rompeu com o déficit regulatório de leis em continuidade ambiental, tendo em vista que nas constituições anteriores não havia capítulos específicos relativos aos sistemas ecológicos e, portanto, tornaram-se ineficientes diante do cenário contemporâneo progressista da sociedade (Art. 225 da CF, Capítulo VI, Do Meio Ambiente).

Seguindo as diretrizes pontuadas na PNMA e na $\mathrm{CF} / 88$, a implementação do SNUC em 2000 e do SEUC-GO em 2002, impulsionou o aparato normativo ambiental, cuja disposição legal destas leis objetiva a criação de unidades de conservação para fins de conservação dos ambientes ecológicos. Os ditames esboçados nos registros dos sistemas de unidades de conservação estipulam, no território nacional e estadual, os parâmetros necessários para criação de áreas protegidas e enfatizam projetos específicos em gestão, manejo e monitoramento socioambiental dentro e no entorno das UC's. (BRASIL, 2000; ESTADO DE GOIÁS, 2001).

Conforme pontuado no SNUC, compreende-se que a abordagem de geodiversidade, geoconservação e patrimônio geológico em Brilha (2005) e Gray (2013) se faz imprescindivelmente relevante ao estudo das paisagens, pois, conforme mencionado pelos autores, à interligação desses três conceitos diz respeito a uma série de elementos que fazem parte dos fenômenos/atividades cíclicas naturais e do habitual das relações sociais diárias.

Segundo Gray (2013), podemos definir geodiversidade como,

a variedade natural (diversidade) de elementos geológicos (rochas, minerais, fósseis), geomorfológicos (formas de relevo, topografia, processos físicos), do solo e hidrológicos. Isso inclui suas assembleias, estruturas, sistemas e contribuições para as paisagens (GRAY, 2013, p. 12)

Para Brilha (2005), geodiversidade incide na seguinte definição, “a geodiversidade consiste na variedade de ambientes geológicos, fenômenos e processos ativos que dão origem as paisagens, rochas, minerais, fósseis, solos e outros depósitos superficiais que são suporte para a vida na Terra”. (BRILHA, 2005, p. 17).

Como avalizado nos conceitos expressos pelos autores, geodiversidade significa a variabilidade da geologia apresentada sobre a superfície terrestre e todos os componentes 
aos quais demanda direta e/ou indiretamente matérias e processos de origem geológica. Processos pedogenéticos, infiltrações hídricas, topografias e relevos, beleza cênica paisagística, recursos minerais, interpretações estratigráficas, atividades de lazer e turismo, são alguns dos exemplos que suscitam da influência da diversidade geológica e/ou da geodiversidade.

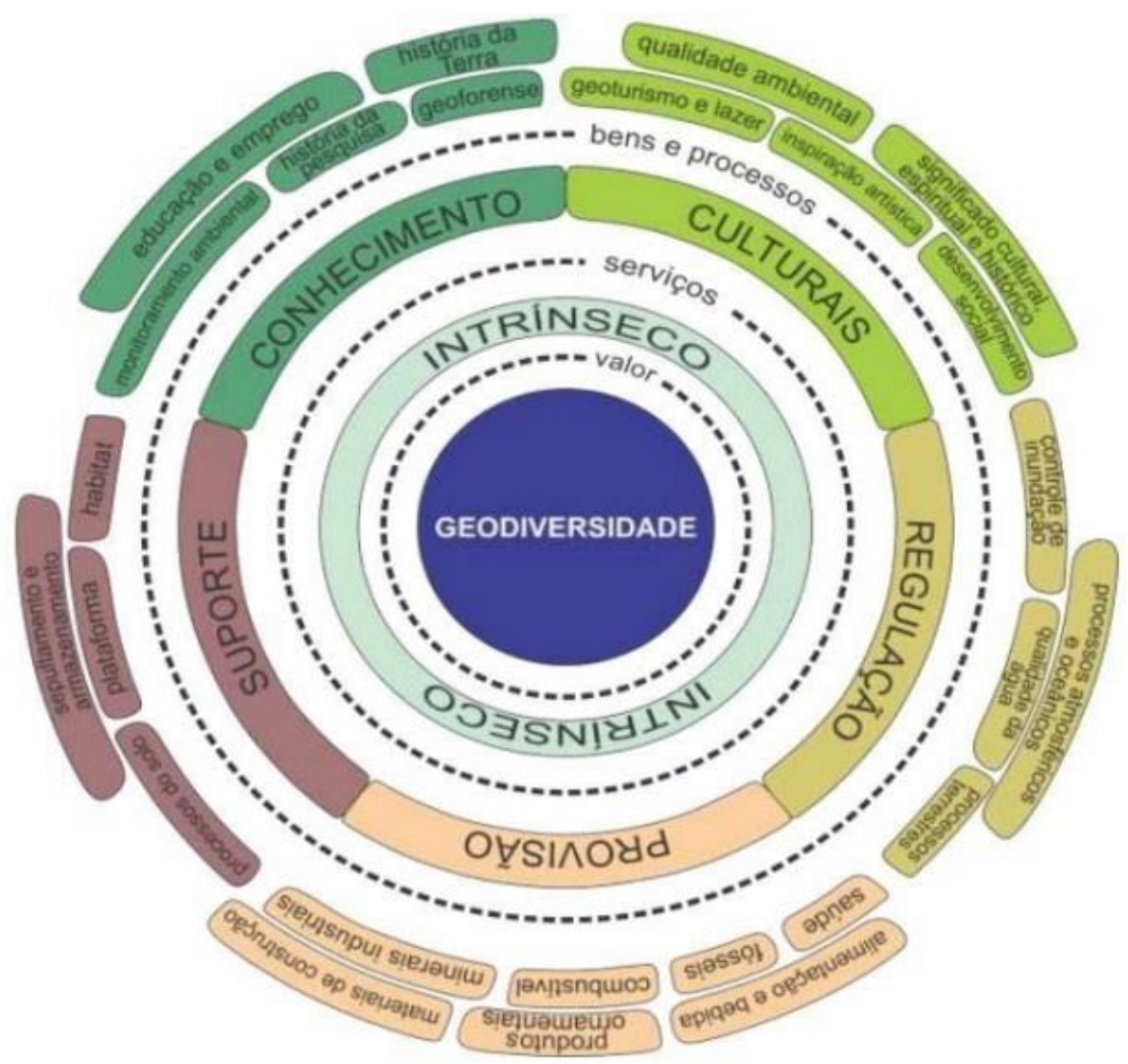

Figura 04: Classificação dos valores de geodiversidade segundo os serviços ecossistêmicos. Fonte: Silva, 2016.

Para tanto, Gray (2013) elaborou uma classificação de valores geológicos expressando a importância destes aos serviços de regulações ecossistêmicas, como observável na Figura 4. Assim, o entendimento valorado pela geodiversidade fez autores como Brilha (2005), cunhar outro termo de referência técnica para integrar a máxima da 
conservação geológica como etapa fundamental em projetos de conservação ambiental, isto é, a geoconservação,

Tem por objetivo a preservação da diversidade natural (ou geodiversidade) de significativos aspectos e processos geológicos (substratos), geomorfológicos (formas de paisagens) e de solo, mantendo a evolução natural (velocidade e intensidade) desses aspectos e processos. (BRILHA, 2005, p. 52).

Como visto na Figura 4, o material elaborado para classificar os valores inerentes a geodiversidade está subdividido em 06 (seis) grandes valores e outras 32 subvalores de interpretação geológica, dos quais são caracterizados essencialmente por: a) serviços de regulação; b) serviços de suporte; c) serviços de provisão; d) serviços culturais; e) serviços de conhecimento e; f) valor intrínseco da própria existência da diversidade geológica.

Dada à configuração que exprime a importância de diagnosticar as relevâncias entre as diferentes litologias geológicas em sua dinâmica com o ambiente, Brilha (2005) é enfático ao relatar o déficit em políticas públicas realizadas na conservação destas áreas naturais em Portugal. O mesmo ressalva a concretude do entendimento da geodiversidade como elemento interpretativo das dinâmicas geológicas, entretanto, condiz que o termo geoconservação e patrimônio geológico haveria de estar significativamente voltados às ações de evidencio legislativo e práticas de cunho político-governamental na elaboração de planos contingencias a supressão geológica. Isto é, há nítida interpretação conceitual entre os três conceitos abordados por este autor, geodiversidade de matriz técnicaeducacional (no qual refere a toda conjuntura sistêmica dos ambientes geológicos) e, geoconservação e patrimônio geológico de matriz técnica-político-jurídico (como requisitos básicos em ações interpessoais que pré-estabeleçam medidas de contingenciamento geológico).

Assim, patrimônio geológico em Brilha (2005), define-se pelo "conjunto dos geossítios inventariados e caracterizados numa dada área ou região" (BRILHA, 2005, p. 52) que proporcionalmente merecem destaque dado sua particularidade geográfica e, concomitantemente, merecem atenção ao corpo de especialistas dos governos, no que tange a elaboração de práticas conservativas em ambientais geológicos para mitigarem atos degradantes em determinada área do patrimônio público para assim serem utilizados como incentivo a sociedade ao reconhecimento dos recursos geológicos, sejam por meio de manifestações de caráter científico, cultural, pedagógico, turístico, dentre outras atividades. Segundo o autor, o patrimônio geológico "integra todos os elementos notáveis que constituem a geodiversidade, englobando, por conseguinte, o Patrimônio Paleontológico, o Mineralógico, o Geomorfológico, o Petrológico, Hidrológico, entre outros" (BRILHA, 2005, p. 54).

Os modelos teóricos utilizados para elaboração deste trabalho fez designarmos o que chamamos de análise integrada para conservação ambiental (Figura 5), já que o diálogo entre as três (03) correntes de pensamentos, qual seja, a de planejamento ambiental, da legislação brasileira ambiental e geodiversidade, geoconservação e 
patrimônio geológico, são intrínsecos ao estudo do PEPa, pois este, detém das características essenciais à elaboração de projetos básicos para o desenvolvimento de uma sociedade sustentável.

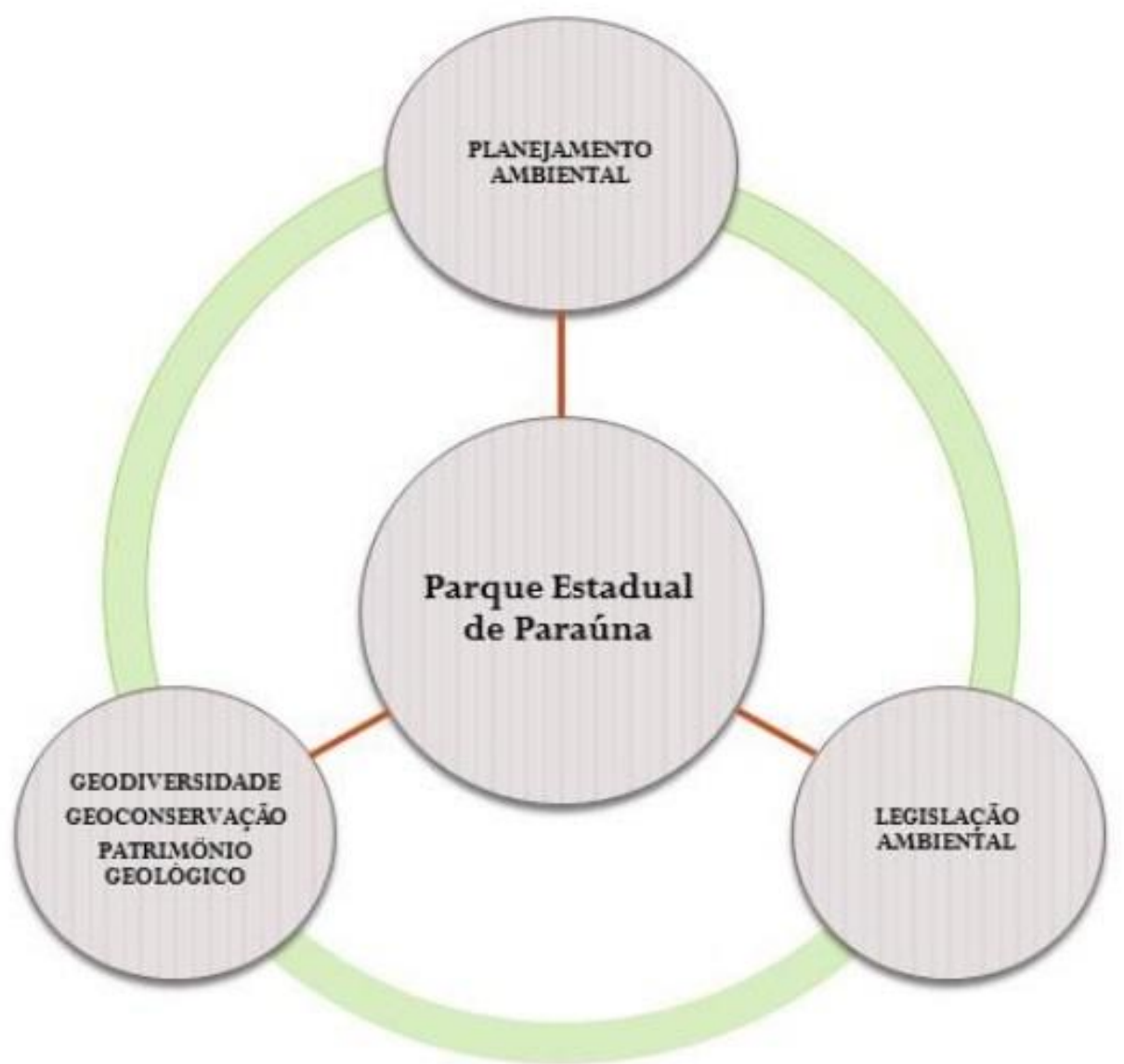

Figura 05: Análise integrada para conservação ambiental: eixos teóricos que fornecem sustentáculo à elaboração da pesquisa.

Org.: Teixeira, D., 2017. 


\section{Resultados e discussões}

A proposta da pesquisa foi em um primeiro momento realizar uma reflexão teórica acerca do assunto da sustentabilidade ambiental englobando posicionamentos de autores que dialogam sobre o planejamento ambiental, geodiversidade, geoconservação, patrimônio geológico e a legislação ambiental brasileira. No segundo momento foi realizado um estudo aplicado abordando os principais déficits materiais relacionados à gestão e preservação das UC's com características de cunho geológico, em nosso caso, dando ênfase ao PEPa, localizado no município de Paraúna/GO.

Neste sentido, conforme alavancado no referencial teórico, o uso da legislação ambiental brasileira se faz pertinente para começarmos a analisar os resultados desta pesquisa. Através dela, iremos pontuar as omissões que ordenamento jurídico abarca em contrapartida as práticas governamentais concretas em geoconservação e patrimônio geológico. No mesmo seguimento, demonstraremos ainda uma incipiente perspectiva de políticas ambientais e/ou ações de manejo junto às UC's como produto final a temática do planejamento ambiental sobre a perspectiva de Ross (2006) e Santos (2004).

Por este ângulo analítico, Brilha (2005) ao verificar as legislações que tratam das temáticas geológicas em Portugal, pontua o baixo teor indicativo nas normativas quando tratado da conservação geológica naquele País, além de uma fervorosa crítica aos órgãos governamentais responsáveis pelas elaborações de políticas em conservação da geodiversidade: “... com efeito, não existe em Portugal uma estratégia de identificação, caracterização e conservação do Patrimônio Geológico" (BRILHA, 2005, p. 87). Ainda segundo o autor, o órgão responsável pela catalogação dos ambientes geológicos "não tem revelado nos últimos anos, nem vontade política nem dispõe dos recursos técnicos necessários para ser, de facto, a instituição responsável pela Geoconservação em Portugal" (BRILHA, 2005, p. 88).

Utilizando da primeira assertiva pontuada por Brilha (2005) - quando objeta à conceptualização terminológica e das estratégias em catalogação dos patrimônios geológicos exercidas em Portugal -, ao verificarmos na PNMA de 1981, a qual trata dos mecanismos e diretrizes sobre o regimento/critérios em políticas ambientais (como plano de Estado brasileiro), cujo objetivo é a "preservação, melhoria e recuperação da qualidade ambiental propícia à vida" (BRASIL, 1981), observamos que não há nenhuma citação simples da terminologia geológica expressada no referido documento. Isto nos presume a pensar que, até a data de 1981, não havia no País, nenhum referencial técnico específico para designarmos a sustentabilidade dos ambientes geológicos em documentos de ordem oficial.

Com a promulgação da CF/88, como pontuado por Silva (2004), as legislações que abordam sobre a proteção dos sistemas ecológicos no território nacional ganharam sublime pertinência no que se refere às leis até então expressadas no País. Entretanto, ao avalizar as premissas comprobatórias em jurisdições sobre o viés conjuntural de conservação de ambientes geológicos, a Carta Magna brasileira não cita, nem específica, 
novamente, à abordagem da preservação dos ambientes litológicos. Pelo contrário, é clara a designação da terminologia "meio ambiente" lotada de conteúdo generalista para interpretação da realidade dos sistemas geoecológicos em sua dimensão, ou seja, há o entendimento de que a principal legislação nacional abrange fatores extremamente amplos em relação a situações específicas para conservação dos ambientes naturais.

Esta conjuntura segue até o presente momento, embora a partir da promulgação do SNUC em 2000, no seu Art. $4^{\circ}$, inciso VII, haja a contrapartida na especificação da proteção de "características relevantes de natureza geológica, geomorfológica, espeleológica, arqueológica, paleontológica e cultural” (SNUC, 2000). Entretanto, percebe-se uma valoração subjetiva no que diz respeito a "características relevantes" da natureza e, não, um modelo conjuntural dos sistemas que integram o patrimônio geológico.

$\mathrm{Na}$ escala estadual, dada à organização política-administrativa do Estado brasileiro, as legislações nacionais enquadram o parâmetro jurídico das respectivas unidades federativas. Embora independentes na elaboração de suas respectivas legislações, as unidades federativas utilizam do ordenamento jurídico federal como pressuposto constitucional no regimento de Leis Internas (BRASIL, 1988).

No que tange a elaboração do SEUC-GO, os mesmos pressupostos técnicos utilizados para criação do SNUC foram reorganizados na legislação estadual, salvo algumas particularidades que serão explicitadas logo abaixo. Entretanto, no que diz respeito à terminologia utilizada para definir os objetivos para criação das unidades estaduais são as mesmas definidas no SNUC. Qual seja, em seu Art. $4^{\circ}$, inciso VIII, define que a legislação pretende "proteger as características relevantes da natureza geológica, geomorfológica, espeleológica, arqueológica, paleontológica e cultural” (SEUC-GO, 2002). Esta citação confirma a crítica ressaltada por Brilha (2005), pois ainda não objetiva um modelo conjuntural de organização e conservação territorial em patrimônio geológico, novamente indicando incipiência governamental no que concerne a novas propostas de organização geoambiental.

Sobre esta égide brasileira, nos vale perguntar, como de fato estão sendo realizadas as práticas conservacionistas em nossos ambientes naturais e, em especial, aos sistemas geoecológicos?

$\mathrm{O}$ estudo aplicado ao PEPa revelou-se irregular quando observado pela função do Estado na aplicação de condutas técnicas estipuladas pela legislação ambiental. A começar pela data de criação do parque, cujo Decreto em Lei Estadual do Estado de Goiás $\mathrm{n}^{\circ}$ 5.568, de 18 de março de 2002, nos dá o indicativo da morosidade da administração pública no exercício de seus poderes. De acordo com o SNUC (2000) em seu Art. 27º, pontua "As unidades de conservação devem dispor de um Plano de Manejo" (SNUC, 2000). Nos ditames abaixo correntes desta Lei, em seu $\S 3^{\circ}$, específica, "O Plano de Manejo de uma unidade de conservação deve ser elaborado no prazo de cinco anos a partir da data de sua criação" (SNUC, 2000). 
Este Art. $27^{\circ}$ do SNUC é um dos que indicam alternância entre o que está proposto em nível federal e estadual, já que o SEUC-GO quando versa sobre a data para elaboração do plano de manejo após criação da UC é diferente do estipulado no SNUC. O texto indicativo no Art. $24^{\circ}$ do SEUC-GO, do qual dispõe que toda UC deve dispor de um plano de manejo, $\S 3^{\circ}$ indica, "O plano de manejo de uma unidade de conservação deverá ser elaborado no prazo máximo de dois anos, a partir da data de sua criação" (SEUC-GO, 2002). Constata-se que, após 15 anos da criação do PEPa, a respectiva UC ainda não tem plano de manejo (http://www.secima.go.gov.br/pagina/ver/12999/unidades-deconservacao). Outro fator que nos chama atenção é que a regularização fundiária ainda corre em processo judicial, demonstrando que a aplicação dos projetos de planejamento e contingenciamento ambiental em Goiás estão paralisados.

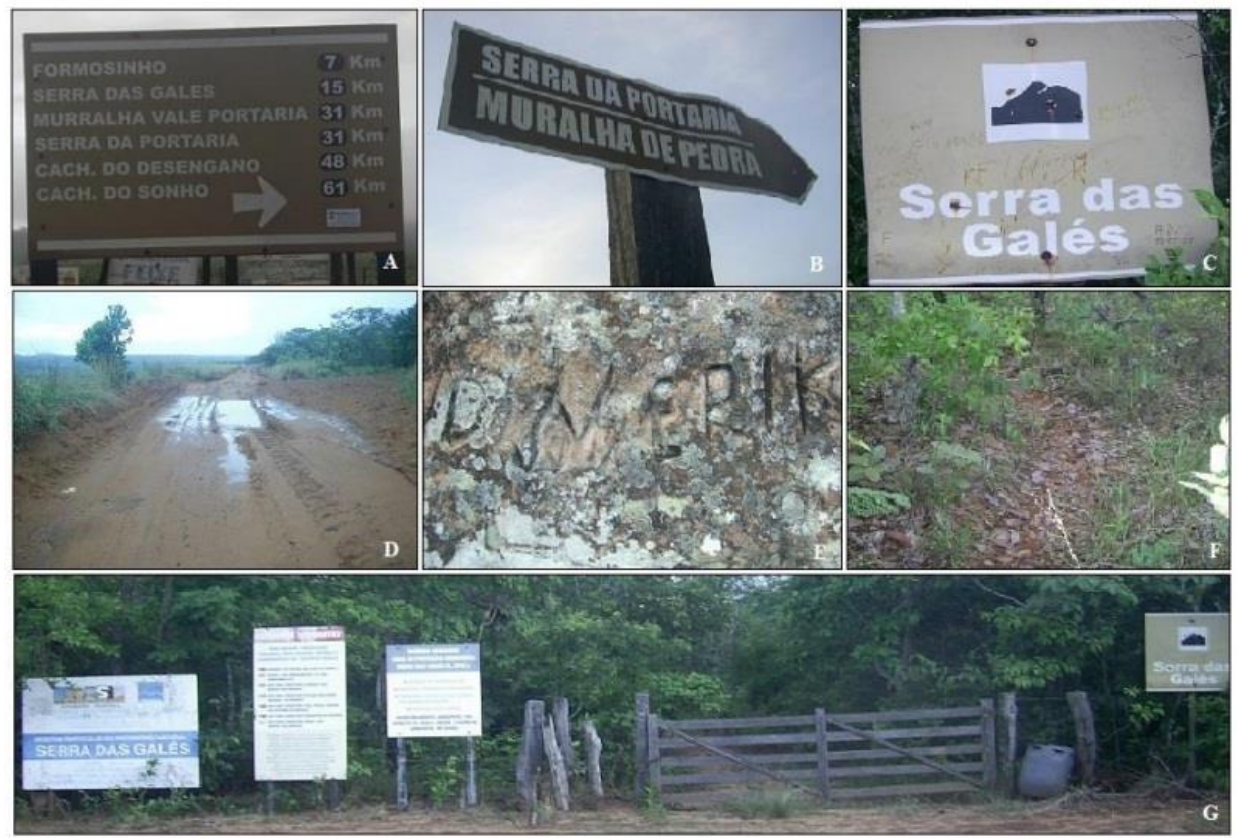

Figura 06: Registros fotográficos realizadas em campo: (a) Trevo de acesso ao PEPa e outros pontos turísticos de Paraúna; (b) Placa informativa de acesso a Serra da Portaria e Muralha de Pedra; (c) Placa acesso à Serra das Galés; (d) Estrada de chão acesso PEPa; (e) Escritas nas rochas areníticas do PEPa; (f) Trilha interna ao Parque; (g) Acesso principal à Serra das Galés.

Acervo: Dos autores.

Org.: Teixeira, D. 2017.

Este retardamento em ações efetivas do governo estadual implica em resultados concretos diagnosticados in loco, como por exemplo, a degradação das rochas localizadas no PEPa, estradas de acesso ao Parque com alto índice de periculosidade, déficit em infraestrutura para recepção de turistas e falta de trilhas informativas/educativas são 
algumas indicações reais de que o PEPa necessita estar contemplado com outros olhos pelo Poder Público. Embora haja placas informativas de como se chegar ao Parque, sinalizações sobre prescrições punitivas a quem degradar o patrimônio público, acesso limitado até o interior da UC e lixeiras, estas informações não somam suficiências dentro da concepção atual para uma gestão integrada para conservação ambiental do PEPa (Figura 6).

Nesse sentido, infelizmente deve-se fazer um paralelo com as afirmativas de Brilha (2005) em relação a Portugal e concordar com o autor, quando diz que àquele País a situação política atual não possui nem vontade, nem recursos técnicos necessários para de fato ter um órgão responsável para elaboração de planos contingenciais em políticas para minimizarem os impactos negativos atinentes aos ambientes naturais públicos. Em Goiás, com o estudo aplicado ao PEPa, nos parece compatíveis a argumentação explanada pelo autor.

\section{Considerações finais}

A resolução percebida neste artigo julga um déficit na elaboração de políticas públicas voltadas ao contingenciamento dos ambientes geoecológicos no Estado de Goiás, seja por meio de incentivo do Poder Público e órgãos correlatos na elaboração de perspectivas que gerenciem ações referentes ao planejamento ambiental e, em especial, a conservação dos ambientes naturais em UC's.

Foi demonstrada a falta de articulação jurídica no tocante as normativas que integram com maiores detalhes a conservação dos patrimônios geológicos em nível federal e estadual, considerando que a geodiversidade integra conjunturalmente os processos cíclicos naturais dos sistemas ecológicos.

O estudo aplicado ao PEPa como indicador concreto aos eixos teóricos alavancados, entrevê as consequências de um projeto ambiental deficitário. Nesta mesma perspectiva, é atinente o resultado da pesquisa quando se mostra em pontuar que as prescrições incididas no início do século XXI acerca da abordagem sustentável do planeta carece de maior atenção do poder público na definição de políticas públicas mais eficazes no estado de Goiás em relação as Unidades de Conservação, em especial ao Parque Estadual de Paraúna.

\section{Referências}

BRASIL. Constituição (1988). Constituição da República Federativa do Brasil: promulgada em 05 de outubro de 1988. Acesso em: 31 de maio de 2017.

BRASIL. Lei Federal n. 6.938, de 31 de agosto de 1981. Dispõe sobre a Política Nacional do Meio Ambiente, seus fins e mecanismos de formulação e aplicação, e dá 
outras providências. Presidência da República - Casa Civil, Brasília, DF, 31 ago. 1981. Acesso em: 31 de maio de 2017.

BRASIL. Lei Federal n. 9.985, de 18 de Julho de 2000. Regulamenta o artigo 225, § $1^{\circ}$, incisos I, II, III e VII da Constituição Federal, institui o Sistema Nacional de Unidades de Conservação da Natureza e dá outras providências. Presidência da República-Casa Civil, Brasília. DF. 18 de jul. 2000. Disponível em: < http://www.planalto.gov.br/ccivil_03/leis/L9985.html>. Acesso em: 25 de setembro de 2017.

BRILHA, J. B. R. Patrimônio geológico e geoconservação: a conservação da natureza na sua vertente geológica. Lisboa: Editora Palimage, 2005.

ESTADO DE GOIÁS, Lei n. 14.247, de 29 de julho de 2002. Institui o Sistema Estadual de Unidades de Conservação no Estado de Goiás e dá outras providências. Governo do Estado de Goiás - Gabinete Civil da Governadoria. Goiânia, GO. 29 de jul. 2002.

Disponível em:

http://www.gabinetecivil.goias.gov.br/leis_ordinarias/2002/lei_14247.html>. Acesso em: 26 de setembro de 2017.

ESTADO DE GOIÁS, Decreto n. 5.568, de 18 de março de 2002. Cria o Parque Estadual de Paraúna e dá outras providências. Governo do Estado de Goiás - Gabinete Civil da Governadoria, Goiânia, GO. 18 de mar. 2002. Disponível em: Acesso em: 30 de julho de 2017.

GOIÁS (Governo do Estado de Goiás). Secretaria de Indústria e Comércio.

Superintendência de Geologia e Mineração. Geologia do Estado de Goiás e do Distrito Federal. Por MOREIRA, Maria Luiza Osório; et al. Goiânia, GO. 2008.

FERREIRA, Bruno Martins. Geodiversidade no Muncípio de Paraúna. 2016. 82 f. Dissertação (Mestrado) - Curso de Geografia, Universidade Federal de Goiás, Goiânia, 2016.

GRAY, M. Geodiversity: valuing and conserving abiotic nature. Londres: John Wiley \& Sons LTDA, 2013.

GUERRA, Antônio Teixeira. Dicionário Geológico Geomorfológico. Rio de Janeiro: IBGE, 1993.

MMA, Ministério do Meio Ambiente. Cadastro Nacional de Unidades de Conservação. Acesso em: 10 de outubro de 2017.

NASCIMENTO, Marcos A. L. do; RUCHKYS, Ursula A.; MONTESSO NETO, Virginio. Geodiversidade, Geoconservação e Geoturismo: Trinômio importante para a proteção do patrimônio geológico. Natal: Sociedade Brasileira de Geologia, 2008.

PESSÔA, Vera Lúcia Salazar. Fundamentos de metodologia científica para elaboração de trabalhos acadêmicos: material para fins didáticos. Uberlândia: Ufu, 2007. 130 p. 
RADAMBRASIL. Ministério Minas e Energia. Geologia, Geomorfologia, Pedologia, Vegetação e Uso Potencial da Terra - Folha SE.22 Goiânia/Goiás. Rio de Janeiro, 1983. $768 \mathrm{p}$.

ROSS, Jurandyr Luciano Sanches. Chapada Dos Guimarães: Borda da Bacia do Paraná. Revista do Departamento de Geografia-Usp, São Paulo, v. 28, n. 0, p.180-197, jan. 2014.

ROSS, Jurandyr Luciano Sanches. Ecogeografia: Subsídios para planejamento ambiental. São Paulo: Oficina de Textos, 2006.

SANTOS, Rozely Ferreira. Planejamento Ambiental: teoria e prática. São Paulo: Oficina de Textos, 2004.

SILVA, José Afonso. Direito Ambiental Constitucional. 5 ed. São Paulo: Malheiros, 2004.

SILVA, Matheus Lisboa Nobre. Geodiversidade da Cidade de Natal (RN): valores, classificação e ameaças. 2016, 171 f. Monografia no. 426. Departamento de Geologia, Universidade Federal do Rio Grande do Norte, Natal, 2016.

SIQUEIRA, Mariana Nascimento, et. al. Geografia e Ecologia da Paisagem: pontos para discussão. Sociedade \& Natureza, Uberlândia, v. 3, n. 25, p.557-566, dez. 2013.

THOMAS, Bruna Letícia; FOLETO, Eliane Maria. A evolução da legislação ambiental no âmbito das áreas protegidas brasileiras. Revista Eletrônica do Curso de Direito UFSM, Santa Maria, p.734-745, 2011.

Delerman Teixeira do Amaral Neto

Graduado em Geografia pela Universidade Federal de Goiás.

Av. Esperança, s/n - Samambaia, Goiânia - GO, 74001-970

E-mail: ddelerman@gmail.com

Cláudia Valéria de Lima

Doutora em Geologia pela Universidade de Brasília. Professora do Instituto de Estudos

Socioambientais da Universidade Federal de Goiás

Av. Esperança, s/n - Samambaia, Goiânia - GO, 74001-970

E-mail: claudia@ufg.br 